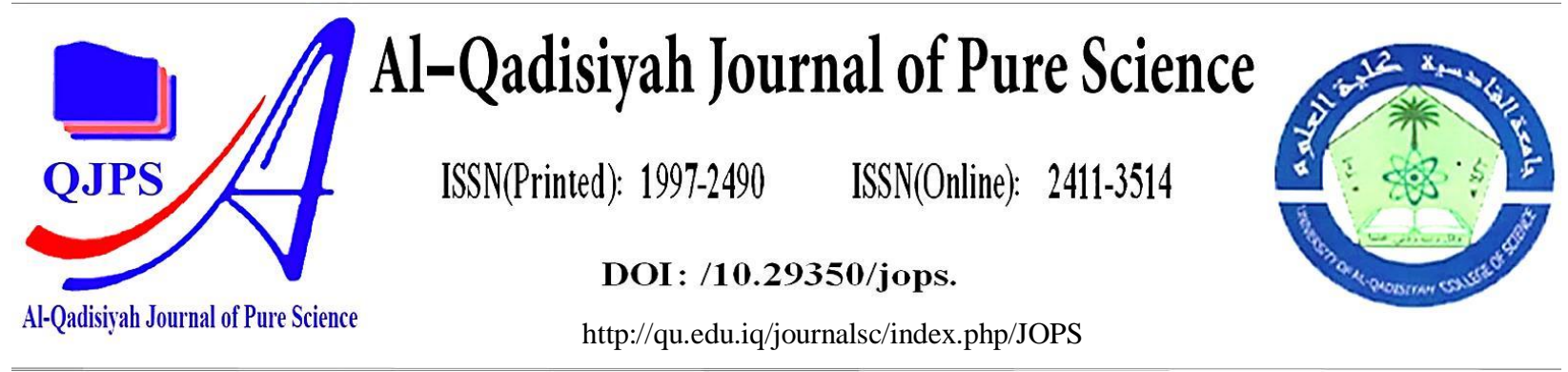

\title{
Study of the histological alterations that result from the effect of Deltamethrin on the earthworm skin
}

\begin{tabular}{|c|c|}
\hline Authors Names & ABSTRACT \\
\hline $\begin{array}{l}\text { Article History } \\
\text { Received on: } 28 / 1 / 2021 \\
\text { Revised on: } 15 / 2 / 2021 \\
\text { Accepted on: } 15 / 2 / 2021 \\
\text { Keywords: } \\
\text { Deltamethrin, } \\
\text { histological, skin, } \\
\text { earthworm } \\
\text { DOI: https://doi.org/10.29350/ } \\
\text { jops.2021.26. } 2.1269\end{array}$ & $\begin{array}{l}\text { Our study aims is to investigate all the morphological and histopathological } \\
\text { changes that occur in skin tissues of the earthworms that exposure to } \\
\text { deltamethrin at concentration (1:2000) g/L. our study is included two groups, } \\
\text { the first group exposed to deltamethrin at a concentration (12.5) mg/L while } \\
\text { the second group is included normal earthworms (control group). The soil } \\
\text { samples collected from local agricultural land randomly in the Daghara in the } \\
\text { Diwaniyah, then add deltamethrin by distributed to the collected soil samples } \\
\text { equally. The experimental group is consists of (20) samples wherever, which } \\
\text { showed that the histological changes of the earthworm that exposure to } \\
\text { deltamethrin (12.5) mg/L is included breaking in the cuticle layer, with clear } \\
\text { degeneration in the longitudinal and circular smooth muscle fibers. } \\
\text { Furthermore, the sub-dermal layer is very thin and destroyed with clear } \\
\text { degeneration of the epidermal cells as well as showed slight congestion of the } \\
\text { blood vessels under the nerve, while the control group consists of (20) soil } \\
\text { samples collected randomly, wherever, demonstrates that the tissue of the } \\
\text { skin of the earthworm was naturally without changes, as a normal cuticle layer } \\
\text { is observed, the epidermis layer is lined with normal epithelial cells, and the } \\
\text { smooth muscle layer appears naturally arranged. In a conclusion, deltamethrin } \\
\text { has histopathological effects on skin tissues of the earthworms that make are } \\
\text { destroyed and leading to damage on the earthworm. }\end{array}$ \\
\hline
\end{tabular}

a. Collage of science, Ecology department, university of Al-Qadissyah, Diwaniyah-Iraq. dhuha.talib@yahoo.com

b. Collage of science, Ecology department, university of Al-Qadissyah, Diwaniyah-Iraq. khadeejaalkhalidi@ gmail.com 


\section{Introduction:}

Deltamethrin is an organophosphorus substance used for insecticide. Deltamethrin is made from chrysanthemum flowers. Using the Deltamethrin in the outdoors and the indoor. Synthetic pyrethroids are a popular type of active ingredient used for pest control because of their effectiveness and ease of use. One such synthetic pyrethroid is Deltamethrin which is a staple active ingredient in various brand name pesticide products (1) (2)

Deltamethrin is a synthetic substance, derived from plant sources (3). Deltamethrin is used for many species of the pest as an insecticide, it works by interacting with the nerve cell by making it send a normal signal by jamming open tiny gates leading to close and open rapidly. Deltamethrin is used in gardens, agriculture, golf courses, pests, indoor and lawns (4) (5).

Deltamethrin is used to kill a wide range of insects, and have several forms such as powder, spray, dust, aerosols, and granules (6). Deltamethrin causes the death of the insects after eats it then causes disorder in the normal activity of the nervous system, however, it has toxicity to the mammals but less than insect, because of the high temperature and size of the body (7), the earthworm is one of the insect that affect by Deltamethrin.

Many reports studied the effecting of Deltamethrin on earthworm, Deltamethrin has long-term toxic effects on the earthworm Eisenia fetida, wherever, the earthworms were exposed to in the soil for 14 days to Deltamethrin, the study showed that the earthworm is decreased with increasing the concentration of deltamethrin in the soil (8).

In another study, using several various concentrations of deltamethrin on mature earthworms (Eisenia fetida) cultured in the soil for (14) days. The study showed that the earthworms that were exposed to deltamethrin for (14) days at a lethal dose (LC50) showed less growth and fewer numbers in every $10 \mathrm{CM}^{3}$ of the soil, also, showed many changes in biomass and cellulase activity (9).

Explanation of the skin and its layers in E. eugeniae that exposed to (5-10) \% of deltamethrin for (2) day demonstrate many morphological changes including coiling, mucus release, and bleeding, clitellar swelling, and body segmentation after exposure (10).

The current study aims to determine all the histological changes of earthworms' skin that isolated from the soil that is exposed to pesticide (Deltamethrin) (1:2000) $\mathrm{g} / \mathrm{L}$ and compares it with normal tissue of earthworm's skin (control group).

\section{Material and methods:}

\section{Sample collection:}

Samples of earthworms were collected (through the presence of the saddle) from one of the orchards of the Daghara in the city of Diwaniyah on (September 2019 - December 2019), as the orchard contained many plants, including palms, citrus, grapes, apples, and many more. Wild plants, as samples of worms, were collected by digging the soil at a depth of (1-3) meters with a field shovel 
along the cliff of a watercourse and making all Laboratories tests in the College of Science / University of alqadisiyah.

Twenty plastic containers (diameter was (40) $\mathrm{cm}$ with height was (70) $\mathrm{cm}$ ) were constructed (20) for the experimental group are consist of (2000) gram of soil then added Deltamethrin at (12.5) $\mathrm{mg} / \mathrm{L}$ and another (20) soil samples are considered as control group (don't treat), both of plastic containers types without cover for allowing to ventilation, collected earthworms with continuous moisturizing with water obtained from the waterway in the orchard from which the worms were taken, then keeping of the earthworms in the container then left for (7) day for acclimatization in laboratory conditions at a temperature of $30-25^{\circ} \mathrm{C}$.

\section{Histopathological examination:}

At the end of the experiment on the first day, the seventh day, and the fifteenth day of adding the deltamethrin, the earthworms were washed with the conductor on which the macroscopic study, and the histopathology handling (11) as follows:

\section{A- Washing:}

This step included extracting the samples from the fixative solution (10\% Formalin and washing them with $70 \%$ ethyl alcohol to remove the fixative.

\section{B- Clearing \& Dehydration:}

Removing of the water was done by running an ascending series of ethyl alcohol $(50 \%, 70 \%, 80 \%$, $90 \%, 95 \%$, absolute) for two hours at each concentration, and xylene was leached for 2 - 3 hours.

\section{C- Impregnation:}

Paraffin War used paraffin wax with a melting point of $(58)^{\circ} \mathrm{C}$.

\section{D- Embedding:}

Molds of wax were made containing fixed samples of samples by confining the molten wax in special plastic molds.

\section{E-Trimming:}

The samples were trimmed by using a sharp blade to get rid of the excess wax and then installed on the base of the rotating microtome.

\section{F- Staining and Mounting:}

To obtain dyed tissue slices, the wax must be disposed of as a predominant material, as the loaded and containing slices were placed on the sample samples in xylene for ten minutes and then passed downward concentrations of ethyl alcohol (absolute, 90\%, 80\%, 70\%, 50\% For two minutes at each 
concentration, then dyed with hematoxylin dye for one minute, then washed with tap water for five minutes, then doused with eosin dye for one minute and placed in acid alcohol for one dip, after which it was transferred to an ascending series of ethyl alcohol concentrations $(50 \%, 70 \%, \%) .80,90 \%, 95 \%$, absolute) for two minutes for each concentration and after that, and then leaching it with xylene for ten minutes, then it was loaded with Canada balsam to permanently saturate it after putting the cover slide and placing the slices on the hot plate to dry and be ready for microscopic examination. Then read the histopathological changes under microscope.

\section{Results:}

Our results showed histopathological changes of the earthworm skin that exposure to deltamethrin (12.5) $\mathrm{mg} / \mathrm{L}$, which breaking in the cuticle layer, with clear degeneration in the longitudinal and circular smooth muscle fibers comparison with a control group. Furthermore, the subdermal layer is very thin and destroyed as showed in Figure (1), with clear degeneration of the epidermal cells as showed in figure (2), and a clear breakdown of the cerebral nerve ganglia as in Figure (3).

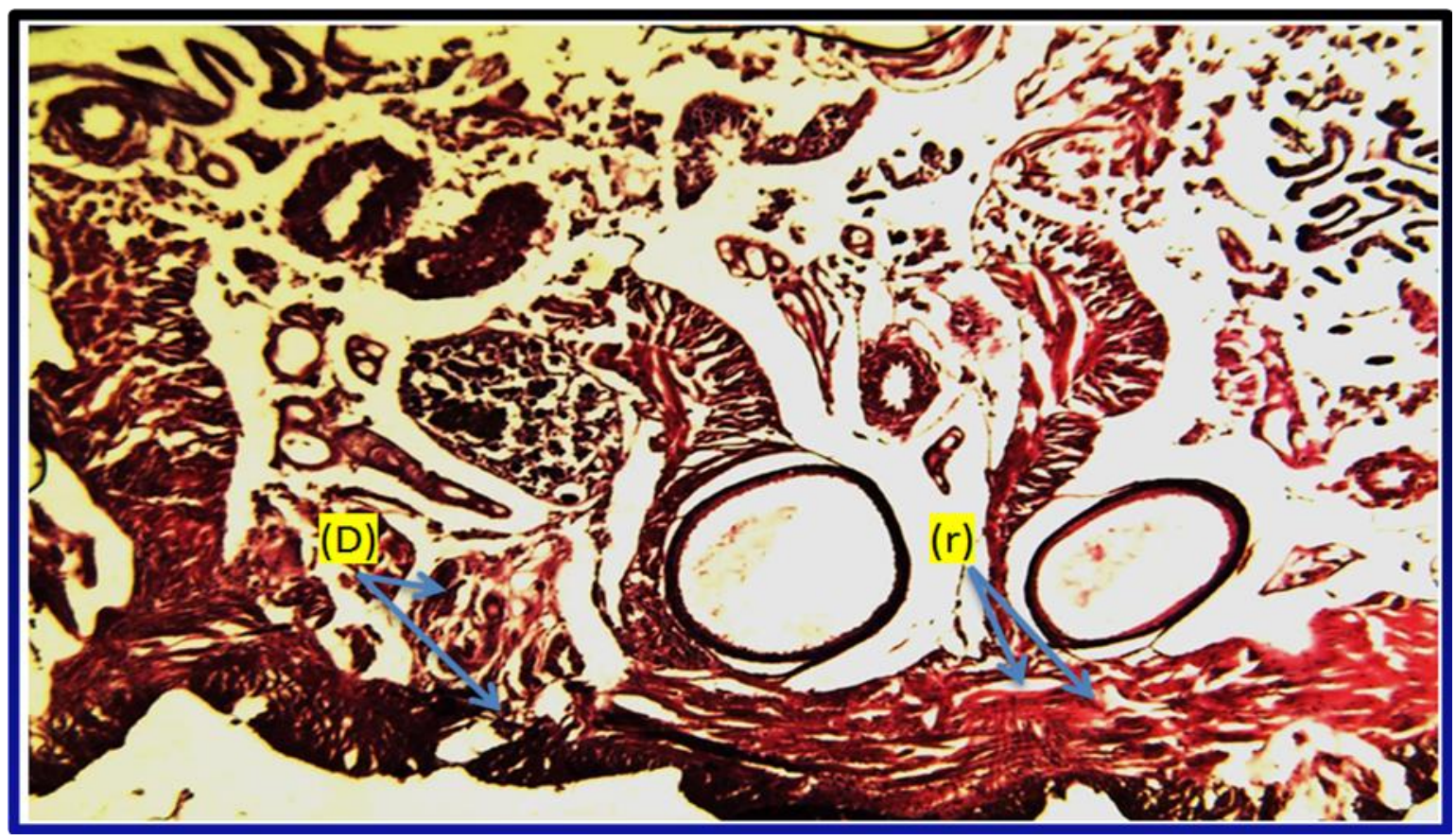

Figure (1): Earthworm skin was exposed to deltamethrin (12.5) $\mathrm{mg} / \mathrm{L}$ showed bursts and breaks into the cuticle layer (r) with clear degeneration in the longitudinal and circular smooth muscle fibers (D). The hypodermis appears very thin and fractured $(10 \times \mathrm{H} \mathrm{\&} \mathrm{E})$. 


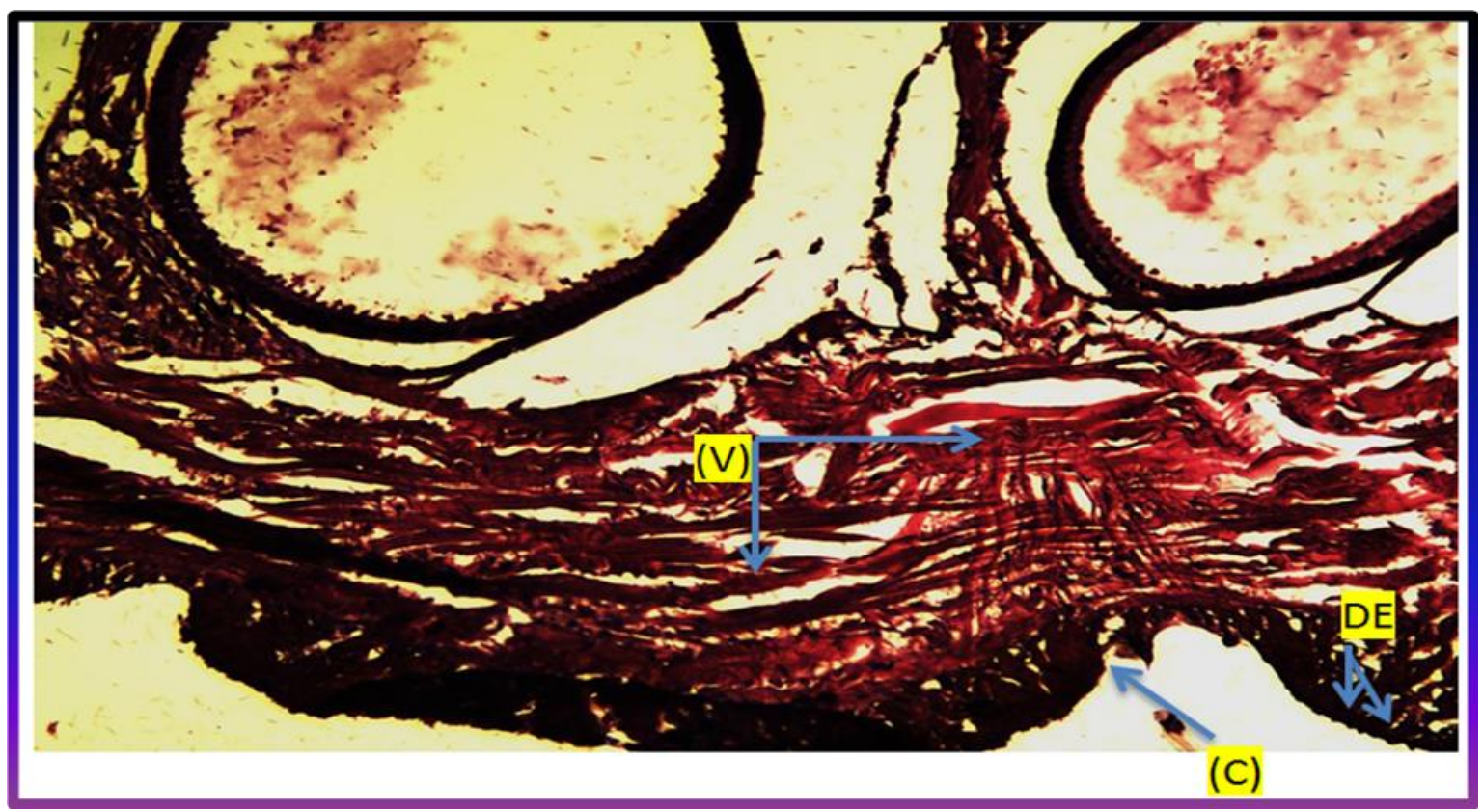

Figure (2): Earthworm skin that exposure to deltamethrin at (12.5) $\mathrm{mg} / \mathrm{L}$ that showed A clear degeneration of epidermal cells (DE) is observed $(C)$ and the presence of voids with slight degeneration of muscle fibers (V) among the myofilaments Subdermal layer appears thin and shattered (10 x H \& E)

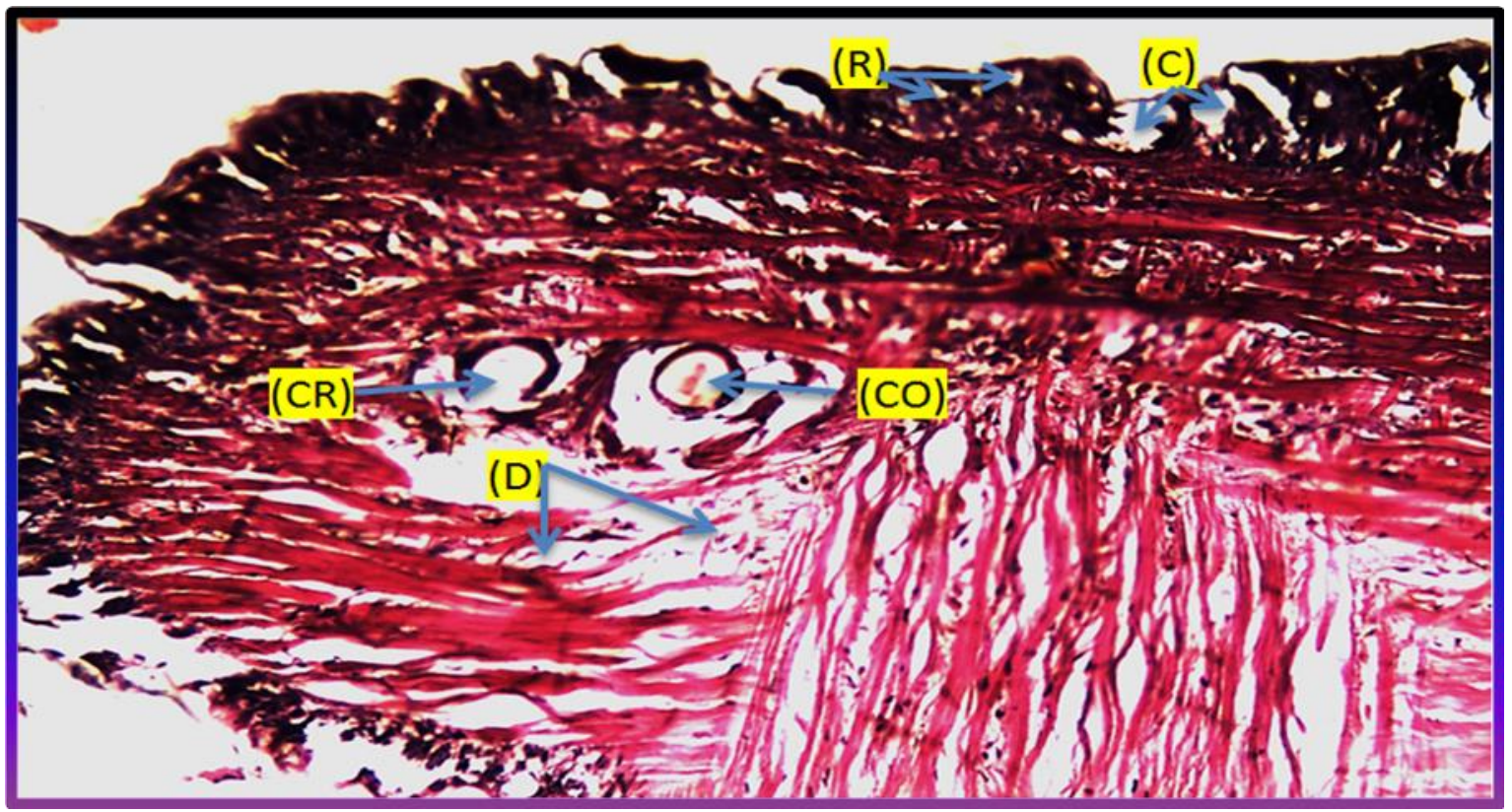

Figure (3): Earthworm skin that exposure to deltamethrin at (12.5) $\mathrm{mg} / \mathrm{L}$ that showed A clear breakdown in the outer body layer, a cuticle (C) with flare-ups and degeneration in the epidermal cells (V) Degeneration and breakdown of the longitudinal and circular muscle fibers

(D) With slight spaces between them, slight vascular congestion (CO) in sub neural b. $v$ An obvious breakdown of the cerebral ganglia $(C R)(10 \times \mathrm{H} \& \mathrm{E})$

The results of the histopathological changes in the skin of the normal earthworm of the control group showed naturally without changes, as a normal cuticle layer is observed, the epidermis layer is 
lined with normal epithelial cells, and the smooth muscle layer appears naturally arranged, as in Figure (4).

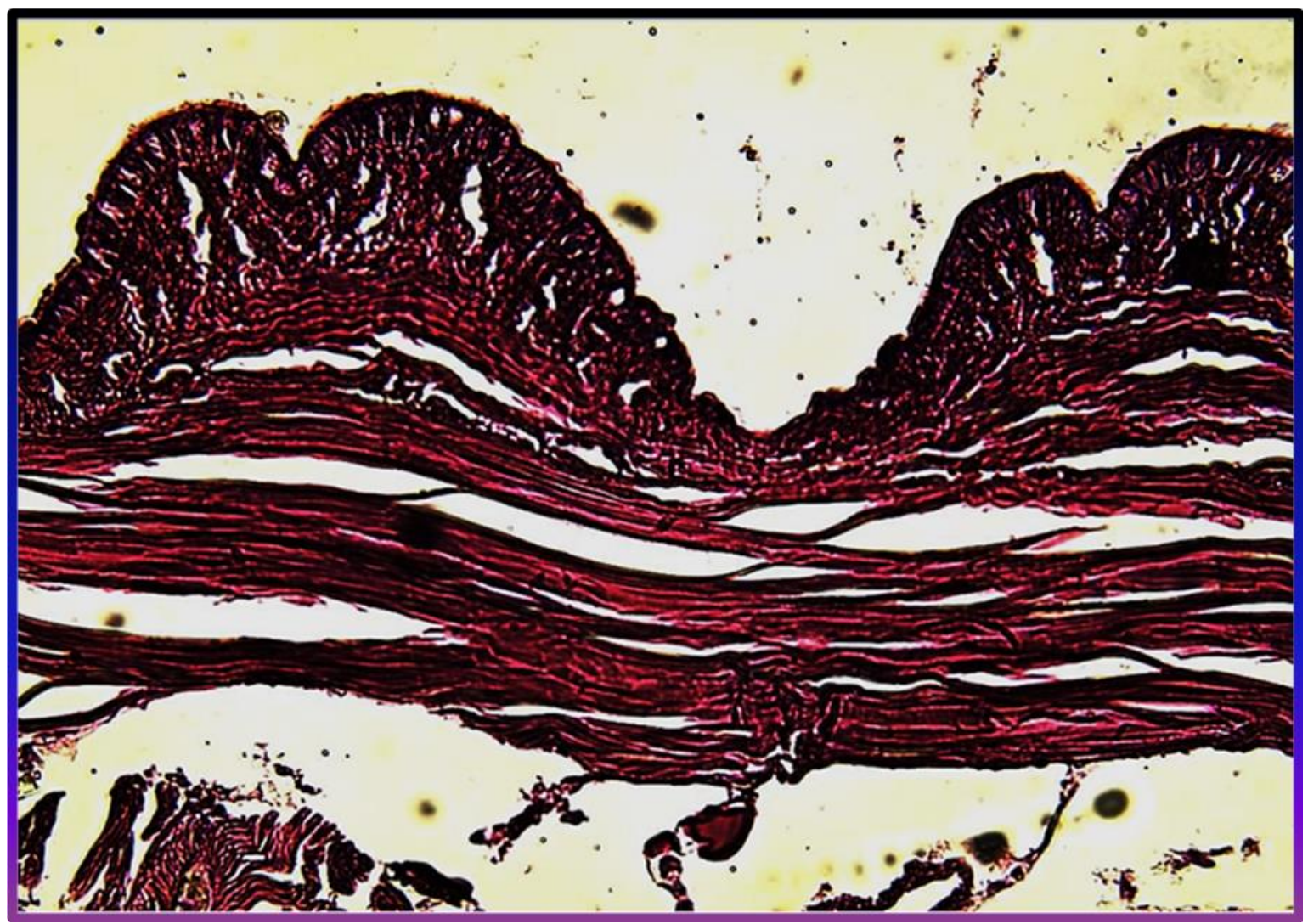

Figure (4): showed a longitudinal section of the earthworm's skin(control group), which appears naturally without changes, as a normal cuticle layer is observed, the epidermis layer is lined with normal epithelial cells and the smooth muscle layer appears naturally arranged. $10 \times \mathrm{H} \& \mathrm{E}$

\section{Discussion:}

Our results demonstrate that there are many histopathological changes of the skin tissue of the earthworm which exposure to deltamethrin (12.5) $\mathrm{mg} / \mathrm{L}$ on the first day, the seventh day, and the fifteenth day. The histopathological changes are included breaking in the cuticle layer, with clear degeneration in the longitudinal and circular smooth muscle fibers. Furthermore, the subdermal layer is very thin and destroyed. Also, there is clear degeneration of the epidermal cells with slight congestion of the blood vessels under the nerve.

While the control group showed histopathological examination of the earthworm skin is normal skin without changes, also, the earthworm skin has a normal cuticle layer and the epidermis layer is lined with normal epithelial cells with the normal smooth muscle layer.

An earthworm has an important impact on soil fertility and soil permeability, but it remains to be known about the factors that influence earthworm abundance and species diversity in agricultural soil and the impact of earthworm diversity on soil processes. Earthworms are one of the most suitable soil 
organisms to be used as key indicator organisms to assess soil pollution by chemicals. There is a need to measure the lethal effects of many toxic substances commonly use in the field of agriculture and evaluate the effects on earthworms. Organophosphate is used by farmers for protecting the crops from chewing, sucking, and boring insects. The study suggested that the toxic effects of Organophosphate are mediated through its effect on the morphological and structural integrity of the tissues (12).

Deltamethrin has long-term toxic effects on the earthworm, wherever the results showed that deltamethrin has a cytotoxicity effect, leading to decreasing in the earthworm numbers by increasing the concentration of deltamethrin in the soil (13).

Morphological alterations and histological effects of an organophosphorus on earthworm is a stable fact, histological changes are included body ruptures, bloody lesions, and internal excessive formation of glandular cell mass and disintegration of circular and longitudinal muscles, which failed to regulate the internal coelomic pressure, leading to fragmentation in earthworms (14).

Histopathological effects of pesticide on earthworm, after exposure to the organophosphorus compounds such as deltamethrin, that results in several histopathological alterations such as defective cocoons with increasing the used pesticide level. Histopathological alterations are rupture of longitudinal muscle, chloragogenous tissue, extra-villous and fused growth, and necrotic cell leading to rupture body wall (longitudinal and circular muscles, epidermis) (15).

Deltamethrin has a direct effect on mature earthworms in the soil at the cell level, wherever, causes a high percentage of earthworm mortality, growth inhibition, and cellulase activity. Earthworms exposed to deltamethrin showed toxic effects on growth and cellulase activity (16). There is a clear and strong effect of deltamethrin on the earthworm. The morphological changes of the earthworms that are exposed to the deltamethrin are included coiling, clitellar swelling, mucus release, and bleeding then showed body segmentation (17).

The study was determining the morphological and histopathological changes by used organophosphate on the body wall of both earthworms Metaphire posthuma and Lampito mauritti. The result showed that organophosphate has direct toxic morphological and histopathological effects on the earthworm tissues. The study found that the histopathological alterations are degenerative changes in whole tissues, multiple ruptures at body length and oozing of coelomic fluid, nod like glandular appearance on the clitellum and posterior region in the earthworm. Furthermore, there are many changes in the earthworm Metaphire posthuma show coiling with the release of copious amount of mucous with partial disruption of segment and degradation of the body wall (18).

Many scientific studies and reports specialized in the effect of the organophosphorus compounds such as deltamethrin on histopathological and morphological alterations of the earthworm, results of these studies showed that it supports and agrees with our finding (19) (20) (21) (22). 


\section{Conclusion:}

In a conclusion, deltamethrin (12.5) $\mathrm{mg} / \mathrm{L}$ has histopathological effects on skin tissues of the earthworms that make are destroyed, our studies recommend use another dose or another pesticide in the soil.

\section{References:}

1-Lu Q, Sun Y, Ares I, Anadón A, Martínez M, Martínez-Larrañaga MR, Yuan Z, Wang X, Martínez MA. (2018). Deltamethrin toxicity: A review of oxidative stress and metabolism. Environ Res. ;170:260-281.

2- Amin, K. A., \& Hashem, K. S. (2012). Deltamethrin-induced oxidative stress and biochemical changes in tissues and blood of catfish (Clarias gariepinus): antioxidant defense and role of alphatocopherol. BMC veterinary research, 8, 45.

3- yas Lahmood, W. (2018). Effect treatment the soil by some pesticide jungles on antagonistic ability for fungus Trichoderma harzianum against rice diseases fungi. Al-Qadisiyah Journal of Pure Science, 22(3), $142-151$.

4- A.M., M., \& Th.M., W. (2018). Molecular and Histological Study of the Effect of Trade Pesticide Chlorpyrifos on Mature Male Rats. Al-Qadisiyah Journal of Pure Science, 22(3), 182 - 193.

5- Sands, B., Mgidiswa, N., Nyamukondiwa, C., \& Wall, R. (2018). Environmental consequences of deltamethrin residues in cattle feces in an African agricultural landscape. Ecology and evolution, 8(5), 2938-2946.

6- Abdel-Khalik MM, Hanafy MS, Abdel-Aziz MI. Studies on the teratogenic effects of deltamethrin in rats. Dtsch Tierarztl Wochenschr. 1993 Apr;100(4):142-3. PMID: 8486089.

7- Choe DH, Campbell K. Effect of feeding status on mortality response of adult bed bugs (Hemiptera: Cimicidae) to some insecticide products. J Econ Entomol. 2014 Jun;107(3):1206-15.

8- Song Y, Kai J, Song X, Zhang W, Li L. Long-term toxic effects of deltamethrin and fenvalerante in soil. J Hazard Mater. 2015 May 30;289:158-164. doi: 10.1016/j.jhazmat.2015.02.057. Epub 2015 Feb 20. PMID: 25725337.

9- Yajuan Shi, Yajing Shi, Xin Wang, Yonglong Lu, Shifa Yan,(2007). Comparative effects of lindane and deltamethrin on mortality, growth, and cellulase activity in earthworms (Eisenia fetida), Pesticide Biochemistry and Physiology, Volume 89, Issue 1,Pages 31-38.

10-Singh, Shikha \& Tiwari, Rishikesh \& Pandey, Ravi. (2019). Acute toxicity evaluation of triazophos, deltamethrin and their combination on earthworm, Eudrilus eugeniae and its impact on AChE activity. Chemistry and Ecology. 10.1080/02757540.2019.1600679. 
11- Albino, I and capkin, (2007). Histology of rainbow trout exposed to stable the concentration of methio carb or endosulfan. Toxico.patho. 3(3): 405-410.

12-Suneel Kumar And Satyendra M. Singh (2017). Histopathological Changes in Two Earthworm Species after O, O-Diethyl S-(Ethylthio) Methyl Phasphoroditl Toxicity. International Journal Of Science, Environment Issn 2278-3687 (O) And Technology, Vol. 6, No 5.

13- Song Y, Kai J, Song X, Zhang W, Li L. (2015). Long-term toxic effects of deltamethrin and fenvalerante in soil. J Hazard Mater. 30;289:158-164.

14-Chakra Reddy N, Venkateswara Rao J. (2008). Biological response of earthworm, Eisenia foetida (Savigny) to an organophosphorous pesticide, profenofos. Ecotoxicol Environ Saf. ;71(2):574-82.

15-Sekar Gowri \& Ramasundaram Thangaraj (2020) Studies on the toxic effects of agrochemical pesticide (Monocrotophos) on physiological and reproductive behavior of indigenous and exotic earthworm species, International Journal of Environmental Health Research, 30:2, 212-225.

16-Shi, Yajuan \& Yajing, Shi \& Wang, Xin \& Yan, Shifa. (2007). Comparative effects of lindane and deltamethrin on mortality, growth, and cellulase activity in earthworms (Eisenia fetida). Pesticide Biochemistry and Physiology, 89. 31-38.

17-Shikha Singh, Rishikesh K. Tiwari \& Ravi S. Pandey (2019) Acute toxicity evaluation of triazophos, deltamethrin and their combination on earthworm, Eudrilus eugeniae and its impact on AChE activity, Chemistry and Ecology, 35:6, 563-575.

18- Suneel Kumar And Satyendra M. Singh (2017). Histopathological Changes In Two Earthworm Species After O, O-Diethyl S-(Ethylthio) Methyl Phasphoroditl Toxicity, International Journal of Science, Environment ISSN 2278-3687 (O) and Technology, Vol. 6, No 5.

19- Xiao, N., Jling, B., GE,E. and Liu, L. (2006): The fate of herbicide acetochlor and its toxicity to Eisenia fetida under laboratory conditions. Chemosphere, 62(8):1366-1373.

20- Youn, J. (2005): Assessing soil ecotoxicity of methyl tert-butyl ether using earthworm bioassay; closed soil microcosm test for volatile organic compounds. Environ. Pollut. 134(2),181-186.

21- Yvan, C., Rault, M., Costagliola,G., Mazzia ,C. (2005): Lethal and sublithal effects of imidacloprid on two earthworm species (Aporrectodea nocturna and Allolobophora icterica). Boil. Fertility Soil. 41(3).135-143.

22- Zang, Y., Zhong, Y., Luo, Y., Kong, Z.M. (2000): Genotoxicity of two noval pesticides for the earthworm (Eisenia fetida). Environ. pollut.108 (2), 271-278. 